\title{
Influence of Precracking Techniques on Fracture Toughness of Carbon-Carbon Composites
}

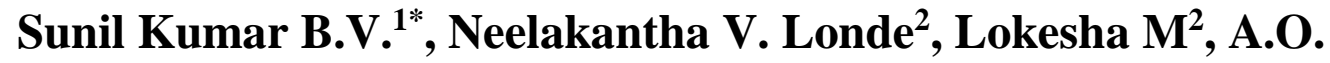 \\ Surendranathan ${ }^{3}$
}

${ }^{1}$ Department of Mechanical Engineering, Canara Engineering College, Mangalore, VTU, Karnataka, 574219, INDIA

${ }^{2}$ Department of Mechanical Engineering, Mangalore Institute of Technology and Engineering, Moodabidri, VTU, Karnataka, 574225, INDIA

${ }^{3}$ Department of Metallurgical and Material Science Engineering, NITK, Surathkal, Karnataka, 575025, INDIA

*Corresponding Author

DOI: https://doi.org/10.30880/ijie.2021.13.06.013

Received 26 October 2021; Accepted 2 January 2021; Available online 31 August 2021

\begin{abstract}
Carbon-Carbon composites are one such material which give designers significant importance for advanced applications over conventional materials. The remarkable characteristics of carbon-carbon composites had made these products initially extremely useful in the field of aerospace and defense applications. Now, they are presently used in many applications such as biomedical implants, glass, and high temperature glass, etc.

In material science, fracture toughness is a trait that depicts the ability of a material to withstand fractures and is one of the most important features in many design applications of any material. A precracked specimen is a sample that is used to accurately assess the distribution of cracks and it is a favored method. This paper describes a comparison of four precracking techniques for carbon-carbon composites using SENB specimen. The potential implications of these techniques on fracture toughness values have been evaluated. The outcome of this work indicates that precracking with a jewel saw is recommended over the other techniques.
\end{abstract}

Keywords: Fracture toughness, precracking, SENB specimen, (a/w) ratio

\section{Introduction}

Materials, in general, play a crucial role in mankind's continuous development at every step. In the recent past, we have seen the production of sophisticated steels and superalloys, which in turn have greatly contributed to the overall development of different technologies impacting lifestyle. With the emergence of fibres, around the $19^{\text {th }}$ century a new class of materials, known as composites, was born. Carbon in general and carbon fibres in particular are central to this new material class (composites). Notably when using composites at high temperatures and under extreme conditions. Carbon is a special element that can show various element's properties in various shapes. Some forms of carbon are extremely hard, like diamonds, although certain types are significantly soft and ductile. Carbon-Carbon is a composite that is considered to be an inverse composite. The goal is to combine the benefit of highly specific compounds. Carbon fibre strength and stiffness with refractory characteristics of the carbon matrix. As fibres are mounted with multidirectional reinforcement in near-net shapes, the outcome is an ideal high-temperature structure [1]-[3]. Carbon composites have been a preferred high-temperature material for the past decade. Technical applications because of the new potential matrix content [4]. 
Carbon-fiber reinforced carbon matrix composites have a 1.7-2.0 gm. /cc density much less than metals and ceramics and thus, make low part weight a significant factor for aerospace applications. Some of the main and most useful properties are lightweight, high strength in non-oxidizing atmospheres at high temperatures (Up to $3000^{\circ} \mathrm{C}$ ), low thermal expansion coefficient, and high heat consumption. Conductivity, high thermal shock resistance, and low recession in high-pressure ablation conditions (higher than that of copper and silver) [5].

These remarkable characteristics have made them extremely useful for aerospace and defence applications such as rocket nozzles, brake discs, leading edges of re-entry vehicles, space vehicle thermal control components, furnace heating, etc. to those for a common man such as glass, biomedical implants, high-temperature glass, and ceramic industry, etc. [5]-[7].

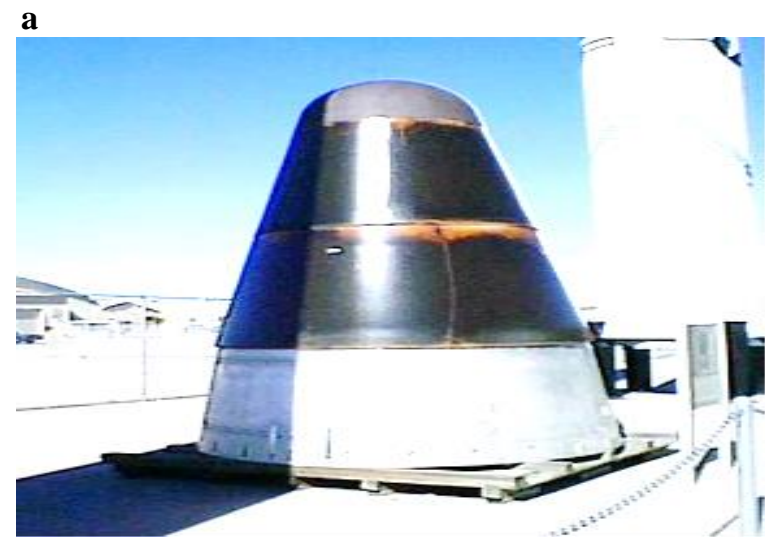

b

Fig. 1- (a) Re-entry nose tip of spacecraft [7]; (b) Aircraft brake [7]

The (LEFM) linear-elastic fracture toughness is defined by the stress intensity factor (K), at which a thin crack starts to form in the material [8]. It is denoted by $\mathrm{K}_{\mathrm{IC}}$, the subscript I indicates the mode I open with a standard tensile stress perpendicular to the crack so the material can be rendered deep enough to endorse shear (mode II) or tear (mode III). Fracture toughness is a quantitative way to convey the resilience of a substance to brittle fracture when there is a crack. A high fracture material can experience a ductile fracture rather than a fracture. Brittle fractures are typical of materials with low toughness to fractures [9].

To apply fracture mechanics methods, experimental measuring and standardization of fracture toughness are important for the evaluation of structural integrity, design of damage tolerances, fitness for use, and residual strength analysis of individual engineering components and structures. [9], [10].

Often, composite materials exhibit a combination of brittle and ductile failure processes. There are many types of fractures in composites such as delamination or interlaminar fracturing, matrix cracking or intralaminar fracturing, fibre breakage, fibre splitting, etc. One of the problems faced in fiber-reinforced polymer composite is also matrix cracking or a crack seemingly running parallel to fibres (Intralaminar) through the thickness. Extensive research on the interlaminar fracture has contributed to the development and standardization of toughness testing on different modes of interlaminar fracture. In recent years, the focus was shifted to assessing intralaminar fracture. Researchers are using the plane strain fracture toughness test methods based on ASTM D5045 (plastics / particulate polymer composite) [11], [12]. These ASTM D 5045 based test methods include loading a precracked notched specimen in either tension (compact tension) or three-point bending. Test methods relevance and several test conditions are similar to ASTM E 399. The specimens for the test of fracture toughness are either compact tension (CT) or three-point Bend (SENB) machined from the laminates according to the specified ASTM D 5045 dimensions as shown in figure 2 [11]-[13].

a

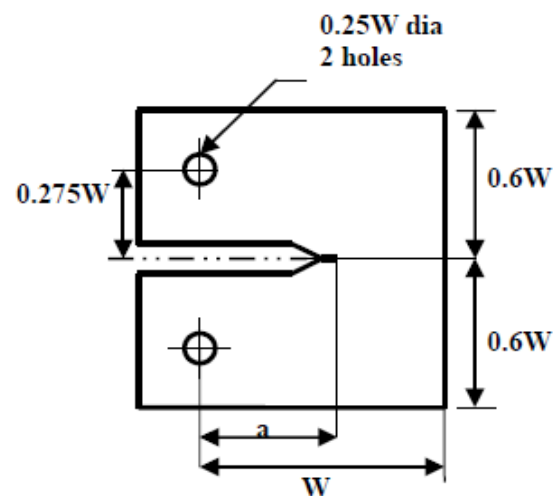

b
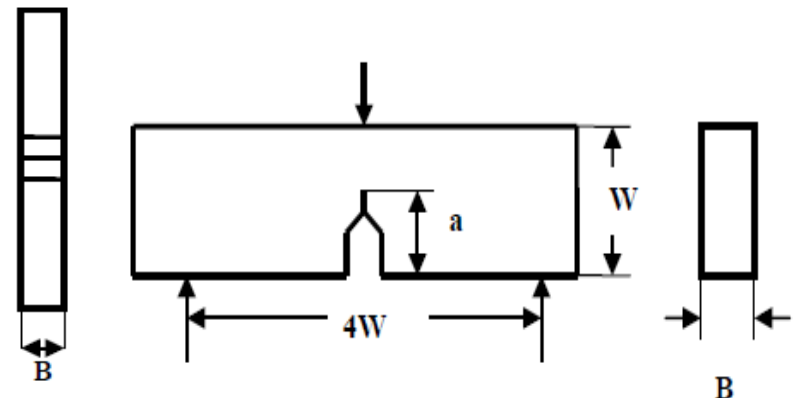

Fig. 2 - (a) Compact Tension specimen; (b) Three Point Bend (SENB) specimen configuration [11]-[13] 
A precracked specimen is a sample that is used to accurately assess the distribution of cracks. It is a favored method for determining the distribution of cracks. To research the fracture mechanics of different materials, first of all, the precracking of the specimens is important. To simplify the research of the findings to make them appropriate, precracking is essential. Therefore, in several papers, many methods were announced to create a natural crack in various polymeric materials [13], [14].

It is often very difficult to create a fatigue precrack in polymer composite materials as the unstable crack propagation will occur and lead to the final fracture of the specimen well before a sufficient long enough fatigue precrack is produced. In the current standards for the determination of fracture toughness of composite materials (ASTM D5045), crack tip root radii as sharp as fatigue precracks can be achieved by using methods that consume less time and require no specialized equipment. Such methods include pressing a sharp razor blade into the notch, use of a blade on a milling machine, use of a coping saw or hacksaw, use of a CBN disc, use of a scoring knife, use of a diamond disc, laser cutting, etc.[15]-[17].

\section{Experimentation Details}

\subsection{Fabrication of Carbon-Carbon Composites}

In this work, the fabrication of carbon-carbon composites is done by a liquid phase impregnation process. The fiber architecture of the material used is 2-D fabric based. This impregnation procedure involves liquid impregnation such as coal tar, oil pitches, and heavy carbon resins.

Firstly, carbon and phenolic laminates were made from carbon fabric prepregs by a compression moulding process. The phenolic resin and $2 \mathrm{D}$ carbon fibre are mixed. Laminates are carbonized up to $1000^{\circ} \mathrm{C}$ temperature, in an inert atmosphere (high purity nitrogen), and then using petroleum pitch it is densified. The densification process involves three steps, pitch impregnation, high-pressure carbonization up to $700^{\circ} \mathrm{C}$ temperature under the pressure of around 1000 bar, and graphitization above $2000^{\circ} \mathrm{C}$. The densification cycles were repeated until the required density of $1.8 \mathrm{gm}$. /cc was achieved.

\subsection{Test Specimens}

The experimental specimens have been prepared to ASTM D 5045 standards [12]. Single edge notch bend (SENB) specimens were used as test specimens as shown in the figure. The $(\mathrm{a} / \mathrm{w})$ ratio taken is 0.45 . Thickness $=\mathrm{B}=10 \mathrm{~mm}$, width $=\mathrm{W}=2 \mathrm{~B}=20 \mathrm{~mm}$, span length $=\mathrm{S}=4 \mathrm{~W}=80 \mathrm{~mm}$ and $\mathrm{crack}$ length $=\mathrm{a}=6 \mathrm{~mm}$.

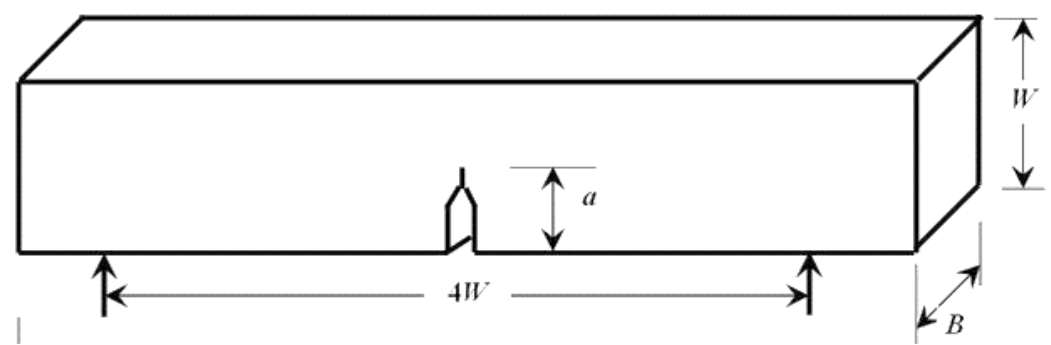

Fig. 3 - Geometry of the SENB specimen used in the work

\subsection{Precracking of Specimens}

The specimens were precracked by four different techniques i.e. precracking by use of a sharp razor blade, scoring knife, jewel saw, and diamond disc. The details of the techniques used are explained in table 1.

Table 1 - Techniques used for precracking

\begin{tabular}{cc}
\hline Technique Used & Maximum Thickness \\
Sharp razor blade & $0.12 \mathrm{~mm}$ \\
Scoring knife & $0.4 \mathrm{~mm}$ \\
\hline Jewel Saw & Tool \\
\hline
\end{tabular}




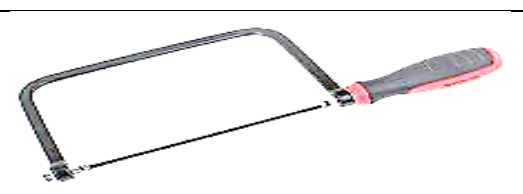

Diamond disc

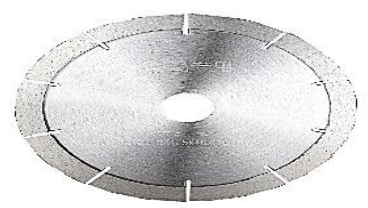

$0.2 \mathrm{~mm}$

\subsection{Testing of Specimens}

Single Edge Notch Bend (SENB) specimens were taken for testing as discussed earlier with width $\mathrm{W}=20 \mathrm{~mm}$, thickness $B=W / 2=10 \mathrm{~mm}$, and span length $\mathrm{S}=4 \mathrm{~W}=80 \mathrm{~mm}$. At least four samples were tested for each condition. The precrack was produced by different techniques as discussed.

Three-point bend tests were conducted on a $50 \mathrm{KN}$ United Calibration Corporation made a universal testing machine with a constant crosshead speed of $1 \mathrm{~mm} / \mathrm{min}$, according to ASTM D5045-14 standard [12]. The tests were performed at a temperature of $28^{\circ} \mathrm{C}$ (Room temperature or RT). The load vs. displacement curves were recorded and the load $\mathrm{P}_{\mathrm{Q}}$ for calculation of fracture toughness was determined. The fracture toughness $\left(\mathrm{K}_{\mathrm{IC}}\right)$ was calculated according to ASTM D5045 standards based on Equation 1, using the geometrical parameters of the samples.

$$
K_{I C}=\left(\frac{P_{Q}}{B W^{1 / 2}}\right) f(x)
$$

Where,

$$
f(x)=6 x^{1 / 2} \frac{\left(1.99-x(1-x)\left(2015-3.93 x+2.7 x^{2}\right)\right)}{(1+2 x)\left(1-x^{3 / 2}\right)}
$$

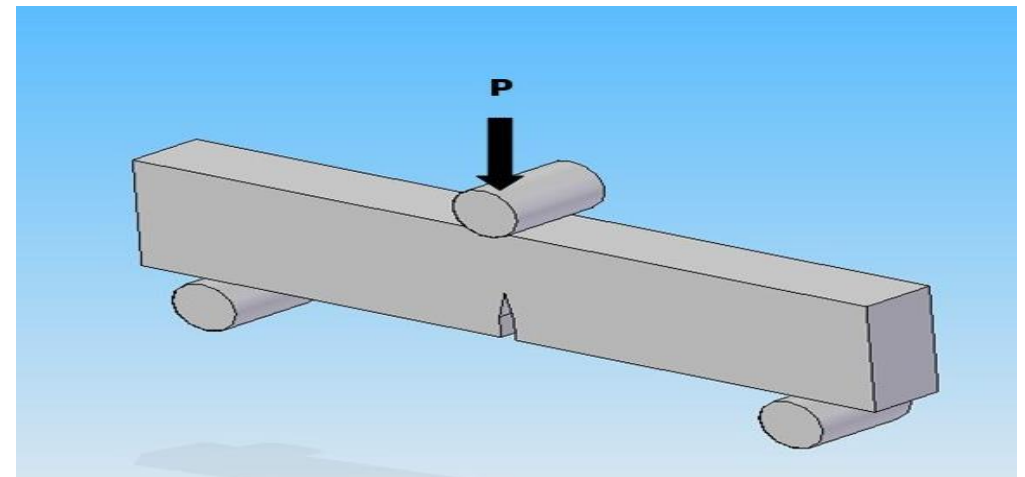

Fig. 4 - SENB specimen geometrical parameters for testing

\section{Results and Discussion}

The results and discussion consist of results of research and review of fracture toughness of carbon-carbon composite having an $(\mathrm{a} / \mathrm{w})$ ratio of 0.45 which is precracked by four different techniques as discussed earlier.

\subsection{Fracture Toughness (KIC)}

The fracture toughness values for precracking by various techniques discussed are obtained from equation 1 . The corresponding value of $\mathrm{P}_{\mathrm{Q}}$ is obtained from the load to displacement curve which is shown in figure 5. The fracture toughness results obtained are shown in table 2 and figure 6 respectively. 


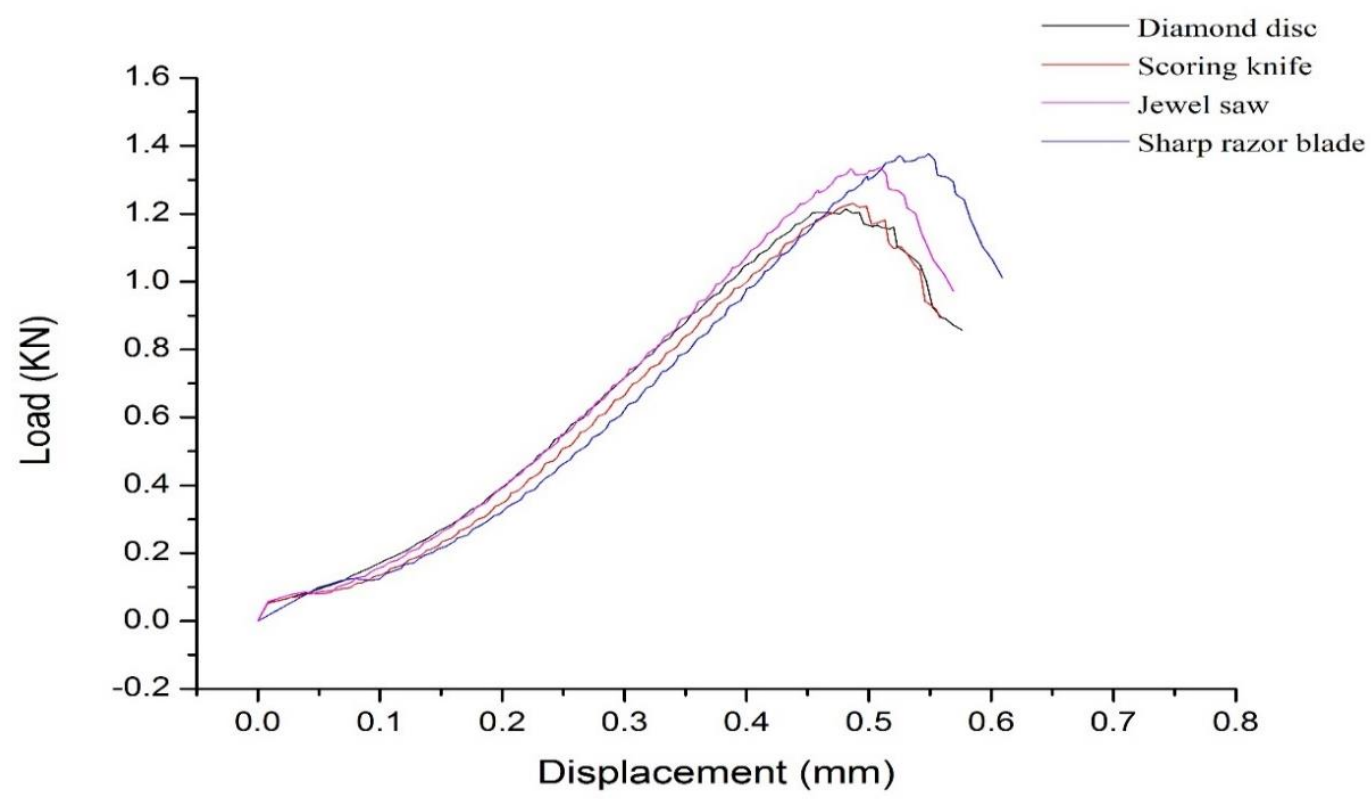

Fig. 5- Load to displacement curve for different precracking techniques

Table 2 - Result of fracture toughness of precracking techniques

\begin{tabular}{ccccc}
\hline Sl. No & Specimen No / (a/w) ratio & Precracking Technique & PQ $(\mathbf{K N})$ & $\begin{array}{c}\text { Fracture Toughness } \\
\text { KIC }(M p a \sqrt{m})\end{array}$ \\
\hline 1 & $\mathrm{~S} 1 / 0.45$ & Sharp razor blade & 1.32 & 8.53 \\
\hline 2 & $\mathrm{~S} 2 / 0.45$ & Scoring knife & 1.17 & 7.56 \\
\hline 3 & $\mathrm{~S} 3 / 0.45$ & Jewel Saw & 1.28 & 8.27 \\
\hline 4 & $\mathrm{~S} 4 / 0.45$ & Diamond disc & 1.15 & 7.43 \\
\hline
\end{tabular}

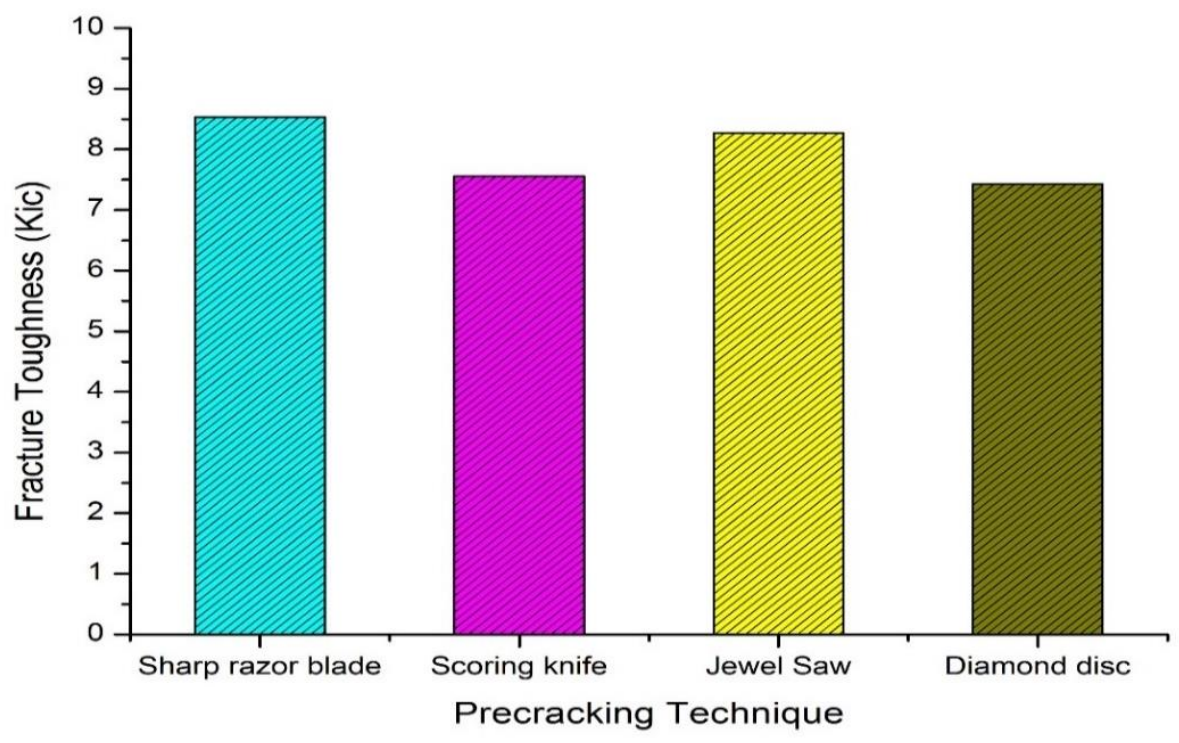

Fig. 6 - Result of fracture toughness of precracking techniques

From the results, it is observed that the specimen precracked by using a sharp razor blade had a higher fracture toughness value, and the specimen which was precracked by using a diamond disc had a lower fracture toughness value in comparison with the other techniques. Since there is no appreciable difference in the fracture toughness between the specimens that are precracked by a sharp razor blade and a jewel saw, this is important. 


\subsection{Optical Microscopy Analysis}

The Olympus built GX51 M optical microscope has been used for taking optical microscopic images. The optical microscopic images describe the precracking type and its corresponding propagation of the crack. Specimens for optical microscopy were polished using a series of emery papers of different grit sizes.
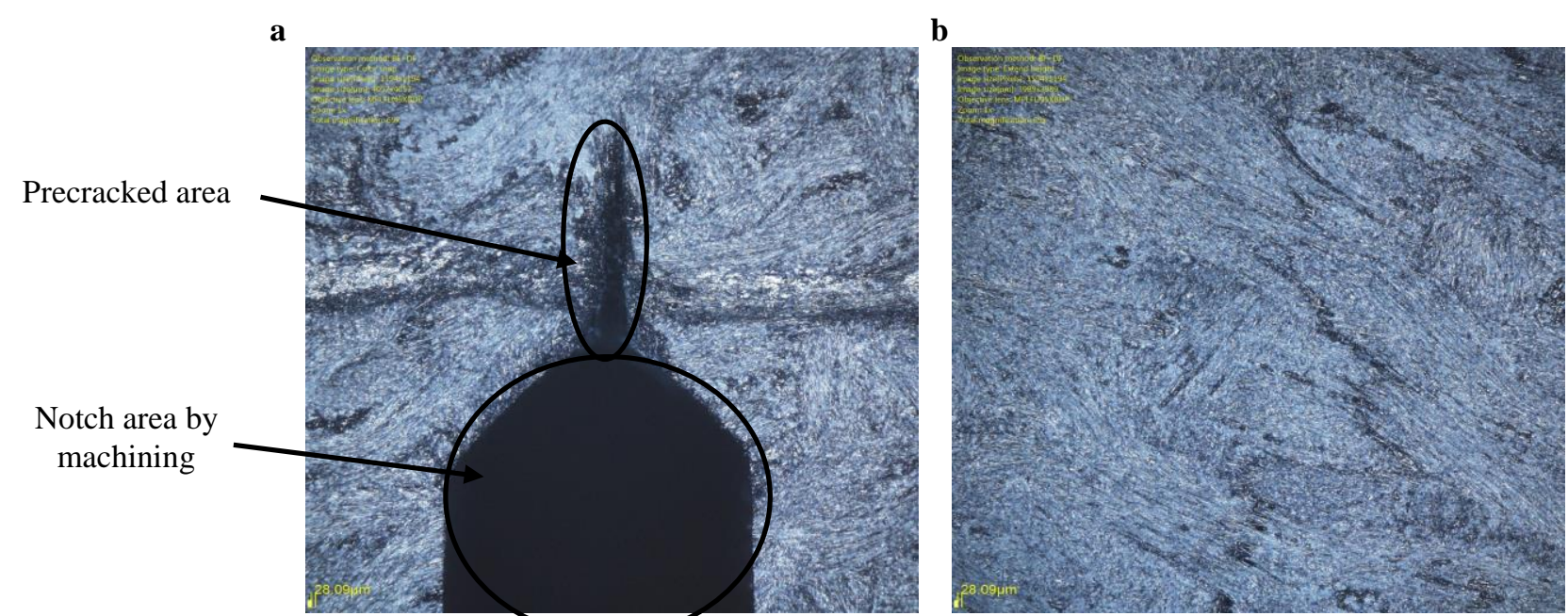

Fig. 7- (a) Precrack a sharp razor blade; (b) corresponding propagation of a crack
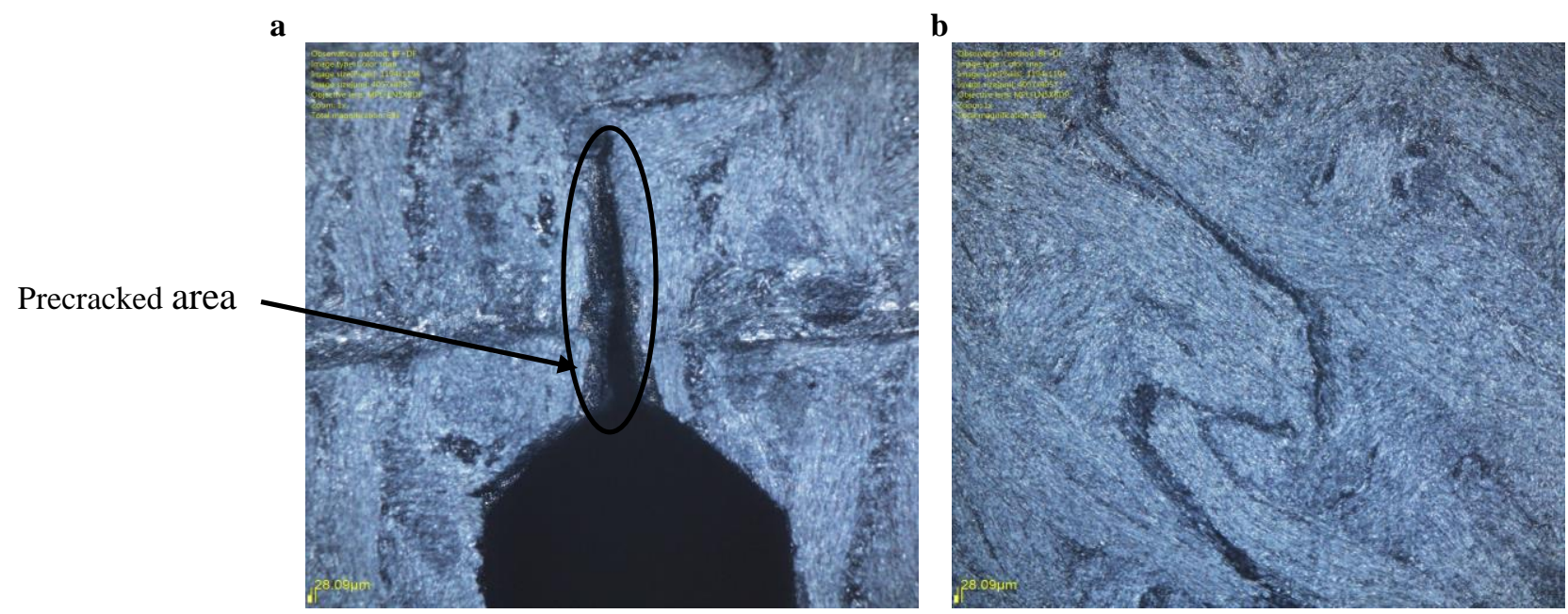

Fig. 8- (a) Precracking by scoring knife; (b) corresponding propagation of a crack
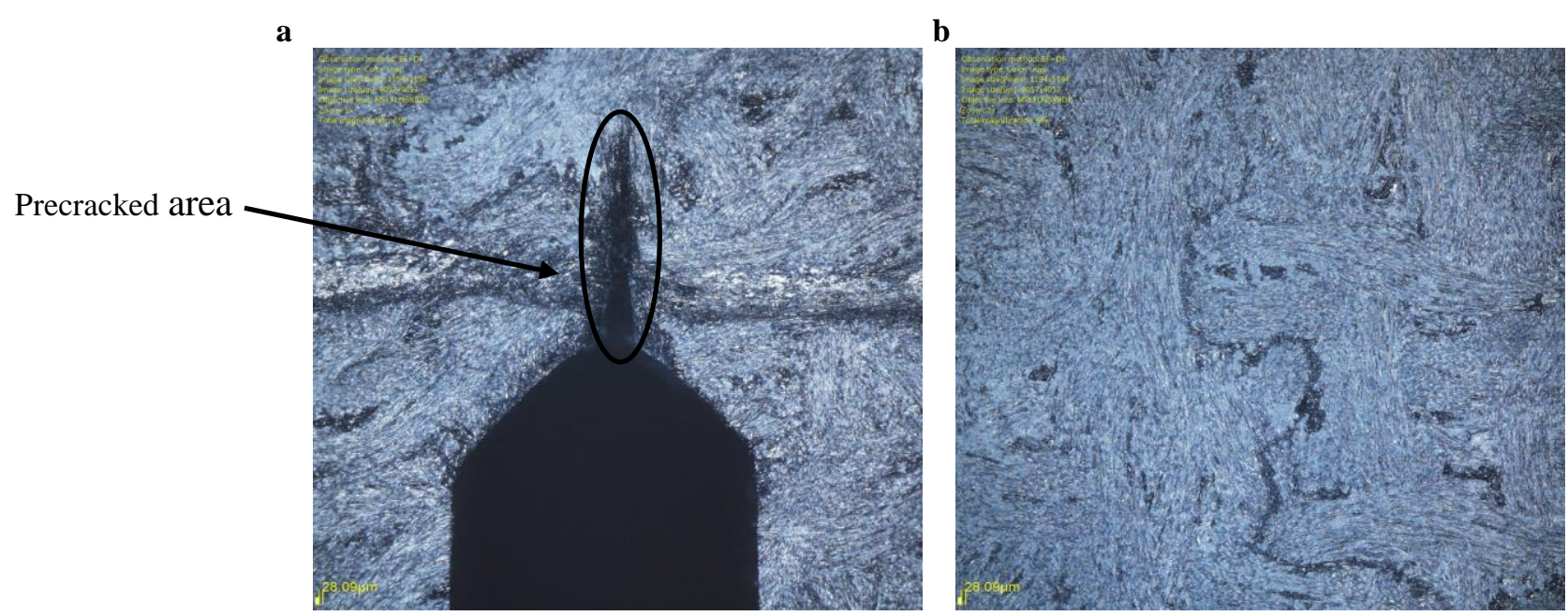

Fig. 9 - (a) Precracking by jewel saw; (b) corresponding propagation of a crack 
$\mathbf{a}$

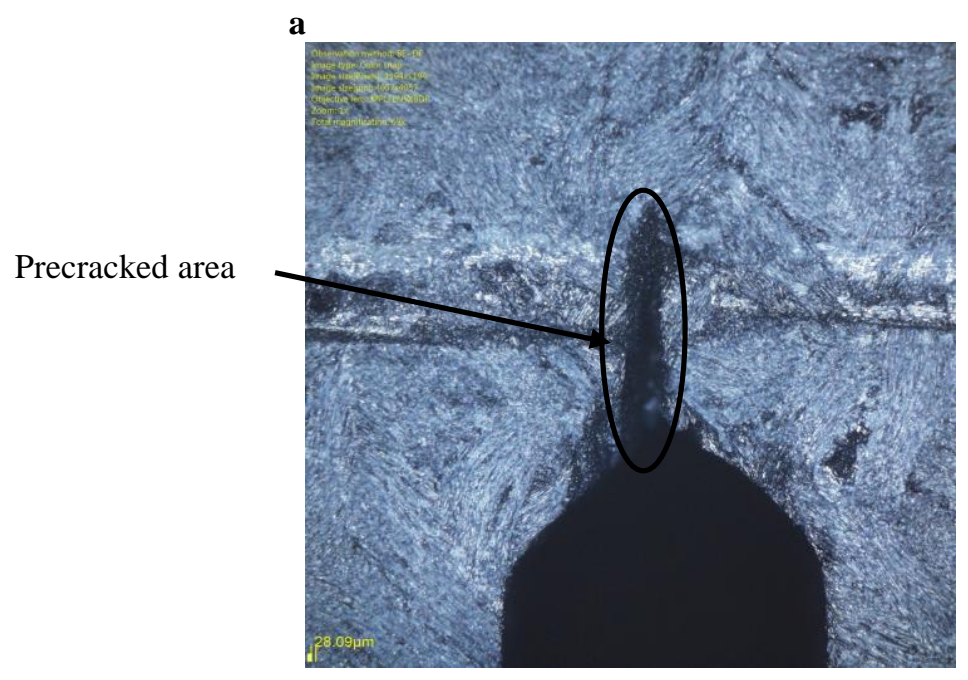

Fig. 10- (a) Precracking by diamond disc; (b) corresponding propagation of a crack

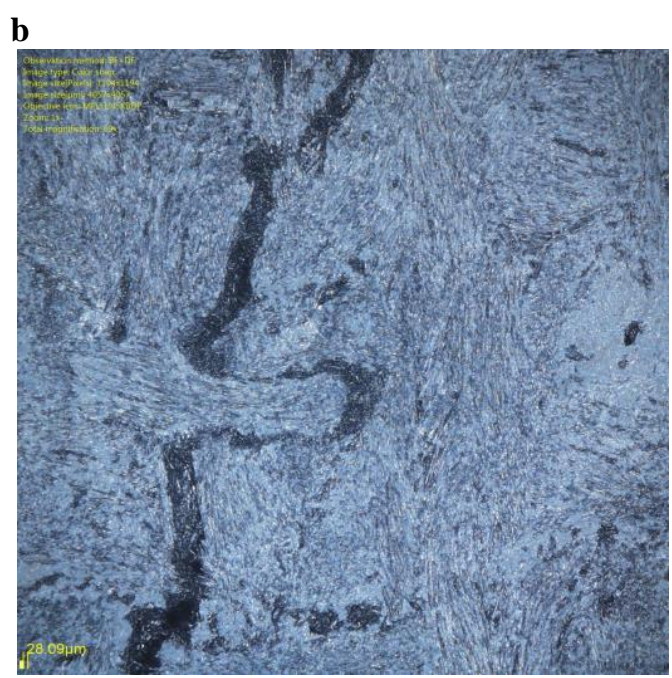

From the above figures i.e. figure 7-10, it is observed that the specimens precracked by using a sharp razor blade and jewel saw had very fine crack propagation and even the size of crack was less in comparison with other techniques. The main reason for this would be the thickness of the material which is used for precracking and the speed of the cutting machine which is used to make a precrack by using a diamond disc. Even from the results, it is observed that the specimen precracked by using a sharp razor blade and jewel saw had a higher fracture toughness value.

The problem associated with the precracking by sharp razor blade is that it is difficult to make a precrack since the material the very hard and brittle. So, in comparison with all the four techniques discussed this work suggests that precracking with a jewel saw is recommended over the other techniques. Further study using many composites to obtain a pattern is needed, but it is clear that different composites need various precracking techniques, and there is no specific precracking technique for each composite, as in the case of metals and alloys.

\section{Conclusions}

From the results, discussion, and analysis the following conclusions are drawn,

- $\quad$ Precracking is one of the important parameters in determining the fracture toughness of a material.

- It is observed that the specimen precracked by using a sharp razor blade had a higher fracture toughness value of $8.53 \mathrm{Mpa} \sqrt{\mathrm{m}}$ and the specimen which was precracked by using a diamond disc had a lower fracture toughness value of $7.43 \mathrm{Mpa} \sqrt{\mathrm{m}}$ in comparison with the other techniques.

- It is observed that the specimens precracked by using a sharp razor blade and jewel saw had very fine crack propagation and even the size of crack was less in comparison with other techniques.

- The problem associated with the precracking by sharp razor blade is that it is difficult to make a precrack since the material the very hard and brittle. Also, there is no appreciable difference in the fracture toughness between the specimens which are precracked by a sharp razor blade and a jewel saw, this is important.

- So, in comparison with all the four techniques discussed this work suggests that precracking with a jewel saw is recommended over the other techniques. It seems the way to obtain accurate fracture toughness values for carbon-carbon composite is by conducting precracking by a jewel saw.

- It is clear that different composites need various precracking techniques, and there is no specific precracking technique for each composite, as in the case of metals and alloys. Further research has to be carried out in this area.

\section{References}

[1] G. R. Devi and K. R. Rao, “Carbon-carbon composites - an overview,” Def. Sci. J., vol. 43, no. 4, pp. 369-383, 1993

[2] T. L. Dhami and O. P. Bahl, "Challenges in Carbon/Carbon Composites Technologies," Carbon Sci., vol. 6, no. 3, pp. 148-157, 2005

[3] T. Windhorst and G. Blount, "Carbon-carbon composites: A summary of recent developments and applications," 
Mater. Des., vol. 18, no. 1, pp. 11-15, 1997

[4] S. Sharma, R. H. Patel, and B. K. Patel, "Comparative study on the carbon-carbon composites developed from petroleum pitch, coal tar pitch, and their mixture," J. Compos. Mater., vol. 54, no. 23, pp. 3395-3404, 2020

[5] L. M. Manocha, "High performance carbon-carbon composites," Sadhana - Acad. Proc. Eng. Sci., vol. 28 , no. 1-2, pp. 349-358, 2003

[6] C. Scarponi, Carbon-carbon composites in aerospace engineering. Elsevier Ltd, 2016

[7] A. Surendranathan, S. B. Kumar, N. VLonde, and G. RaoJ, "Fabrication Methods, Recent Developments and Applications of Carbon-Carbon Composites (CCC): A Review," Int. Res. J. Eng. Technol., p. 1252, 2008

[8] R. K. Nanstad and D. P. Edmonds, "Fracture Toughness.," Press. Vessel Pip. Technol, pp. 507-520, 1985

[9] A. H. M. Ismail, M. S. Risby, A. Ali, S. M. Sapuan, and M. E. Hoque, "Flexural strength and fracture toughness of carbon nanotubes ( CNT's) reinforced epoxy composites," no. 3, 2015

[10] X. K. Zhu and J. A. Joyce, "Review of fracture toughness (G, K, J, CTOD, CTOA) testing and standardization," Eng. Fract. Mech., vol. 85, pp. 1-46, 2012

[11] M. S. S. Prasad, C. S. Venkatesha, and T. Jayaraju, "Experimental Methods of Determining Fracture Toughness of Fiber Reinforced Polymer Composites under Various Loading Conditions," J. Miner. Mater. Charact. Eng., vol. 10, no. 13, pp. 1263-1275, 2011

[12] ASTM International, “(ASTM D 5054) - Standard Test Methods for Plane-Strain Fracture Toughness and Strain Energy Release Rate of Plastic Materials,” ASTM B. Stand., vol. 99, no. Reapproved 2007, pp. 1-9, 2013.

[13] a Szekrényes, "Overview on the experimental investigations of the fracture toughness in composite materials," Hungarian Electron. J. Sci. http//hej. ..., pp. 1-19, 2002

[14] M. S. Cayard and W. L. Bradley, "The effect of various pre-cracking techniques on the fracture toughness of plastics," Icf7. 1989

[15] E. Haddadi, N. Choupani, and F. Abbasi, "Investigation on the effect of different pre-cracking methods on fracture toughness of RT-PMMA," Lat. Am. J. Solids Struct., vol. 13, no. 11, pp. 2012-2026, 2016

[16] J. M. De Souza, H. N. Yoshimura, F. M. Peres, and C. G. Schön, "Effect of sample pre-cracking method and notch geometry in plane strain fracture toughness tests as applied to a PMMA resin," Polym. Test., vol. 31, no. 6, pp. 834-840, 2012

[17] "Xiao1998_Article_EffectsOfPre-crackingMethodsOn.pdf." 